\title{
Risk of Myocardial Infarction in Parents of HIV-infected Individuals: a population-based Cohort Study
}

Line D Rasmussen*1, Lars H Omland², Court Pedersen¹, Jan Gerstoft², Gitte Kronborg³, Janne Jensen4 and Niels Obel2

\begin{abstract}
Background: Previous studies have indicated an increased risk of myocardial infarction (MI) in HIV infected individuals especially after start of highly active antiretroviral therapy (HAART). It is however controversial whether the increased risk of atherosclerotic disease is exclusively associated with the HIV disease and HAART or whether life-style related or genetic factors also increase the risk in this population. To establish whether the increased risk of myocardial infarction in HIV patients partly reflects an increased risk of MI in their families, we estimated the relative risk of MI in parents of HIV-infected individuals.
\end{abstract}

Methods: From the Danish HIV Cohort Study and the Danish Civil Registration System we identified the parents of all HIV-infected patients born in Denmark after 1952 in whom a Danish born mother was identifiable. For each HIV patient, 4 matched population controls and their parents were identified. Cumulative incidence functions were constructed to illustrate time to first Ml of the parents as registered in the Danish National Hospital Registry. Incidence rate ratios (IRR) were estimated by Cox's regression analyses. Due to the confidential type of the analysed data the study was approved by the Danish Data Protection Agency.

Results: 2,269 mothers and 2,022 fathers of HIV patients as well as 9,076 mothers and 8,460 fathers of control subjects were identified. We observed an increased risk of MI in mothers of HIV patients (adjusted IRR, 1.31; 95\% Cl: 1.08-1.60). The strongest association was seen in case the offspring was infected heterosexually (adjusted IRR, 1.59; 95\% Cl: 1.072.35) or by IV drug abuse (IVD) (adjusted IRR, 1.63; 95\% Cl: 1.02-2.60). In fathers of HIV patients the risk of MI was only increased if the offspring was infected by IVD (adjusted IRR, 1.42; 95\% Cl: 1.01-2.00).

Conclusion: Mothers of HIV-infected patients have an increased risk of MI. We presume that this stems from family related life style risk factors, some of which may also influence the risk of MI in HIV-infected patients.

\section{Background}

The introduction of highly active antiretroviral therapy (HAART) has reduced mortality and morbidity dramatically in HIV-infected patients [1]. HAART has, however, been shown to cause a number of metabolic changes and potentially atherosclerotic complications [2,3]. Some studies have indicated an increased risk of myocardial infarction (MI) even in HIV patients not on HAART $[4,5]$. In a study from the Danish HIV Cohort we found a relative risk of MI of 1.39 in patients not on HAART when compared to the background population [4]. The

* Correspondence: linedahlerup@hotmail.com

1 Department of Infectious Diseases, Odense University Hospital, Odense, Denmark

Full list of author information is available at the end of the article risk was further increased following HAART initiation (adjusted relative risk 2.12), and the risk did not increase further during the first 8 years of HAART. This was in contrast to the DAD-study, which concluded that the risk of MI increased progressively with the duration of HAART exposure [6]. Initially the main focus was on use of protease inhibitors, but in 2008 the DAD study found that current exposure to abacavir and didanosine was associated with an increased risk of coronary events [7]. It is however still controversial whether the increased risk of atherosclerotic disease is exclusively associated with the HIV disease and HAART or whether it is also increased due to life-style related or genetic factors. 
A family history of atherosclerotic disease is associated with an increased risk of MI [8]. The association most likely is mediated not only through genetic factors, but also through shared socio-economic and environmental factors affecting life-style e.g. smoking, diet, body mass index, physical activity as well as the use of medical services. Previous studies have adjusted the estimated risk of MI for known cardiovascular risk factors [4-6,9-13], estimated and compared the distribution of risk factors in HIV patients with that of the background population [6,14-16] or simply excluded patients with risk factors from their study [17]. These studies though may be hampered from residual confounding or confounding due to non-measured factors. As a measure of these unaccounted for confounders we aimed to estimate the risk of $\mathrm{MI}$ in parents of HIV-infected individuals. We therefore conducted a population based, nationwide cohort study of the risk of MI in the parents of HIV-infected patients compared to the risk in parents of population controls.

\section{Methods}

The study design is presented in figure 1 .

\section{Setting}

As of 1 January 2007 Denmark had a population of 5.4 million (Statistics Denmark, http://www.statbank.dk), with an estimated HIV prevalence of $0.07 \%$ among adults [18]. Medical care, including antiretroviral treatment, is tax-paid and provided free-of-charge to all HIV-infected residents of Denmark.

\section{Data sources}

We used the unique 10-digit civil registration number assigned to all individuals in Denmark to link the data sources described below.

\section{The Danish HIV Cohort Study}

The Danish HIV Cohort Study, described in detail elsewhere, is a nationwide, prospective, population-based cohort study including all Danish HIV-infected patients treated at Danish hospitals since 1 January 1995 [18]. The data are updated on a yearly basis and include amongst others demographics, route of infection, all CD4 counts, viral loads and antiretroviral treatment.

\section{The Danish Civil Registration System}

The Danish Civil Registration System was established in 1968 and stores information of vital status, residency as well as immigration and emigration on all Danish residents [19]. A 10-digit personal number (Central Person Registry [CPR] number), assigned at birth, uniquely identifies each citizen. Since 1 January 1969 the registry also included identification of parents still alive at this date.

\section{The Danish National Hospital Registry}

The Danish National Hospital Registry was established in January 1977 and records all discharge diagnoses accord- ing to ICD-8 and ICD-10 codes, all operation codes according to IOC codes and since 1995 all hospital outpatient visits for patients treated in Danish hospitals (The International Classification of Diseases $8^{\text {th }}$ revision until the end of 1993 and here after $10^{\text {th }}$ revision - ICD-9 has never been used in Denmark) [20].

\section{Definition of $\mathrm{MI}$}

The date of the myocardial infarction was defined as the first date an individual was registered in the Danish National Hospital Registry with one of the following ICD8 or ICD-10 diagnosis: 410.9, 410.99, I21.0-21.9.

\section{HIV-infected patients and general population control cohort}

The HIV patients were identified from the Danish HIV Cohort Study (figure 1). The index date in these patients was defined as 1 January 1995 or the date of the HIV diagnosis which ever came last. We identified all HIVinfected patients who: 1) were registered in the Danish Civil Registration System, 2) born in Denmark after year 1952 (the registration of parents in the Danish Civil Registration System is incomplete for individuals born before 1953), 3) had a mother born in Denmark, who were identifiable in the Danish Civil Registration System and 4) living in Denmark on the index date.

For each of the HIV-infected patients we identified 4 age- and gender matched population control subjects from the Danish Civil Registration System who: 1) were registered in the Danish Civil Registration System, 2) born in Denmark after year 1952, 3) had a mother born in Denmark, who were identifiable in the Danish Civil Registration System and 4) living in Denmark on the index date of the matching HIV patient.

\section{Study populations (parents)}

We identified all Danish born parents of the HIV-infected patients and population control subjects who were registered in the Danish Civil Registration System (figure 1). Index date of the parents was defined as the start of the Danish National Hospital Registry (January 1 1977) or date of birth of the offspring which ever came last.

\section{Statistics}

We assessed the risk of MI in parents of HIV-infected patients as well as parents of the control cohort subjects. Time was calculated from index date to the first of the following: - date of MI, emigration, death, lost to follow up or 1 June 2008. We used cumulative incidence function to illustrate time to first MI registered in the Danish National Hospital Registry, recognizing death as a competing risk [21]. Incidence rate ratios (IRR) and 95\% confidence intervals for $\mathrm{MI}$ as estimates of relative risks were calculated using Cox proportional-hazards regression. Results were stratified on mothers and fathers. Further 


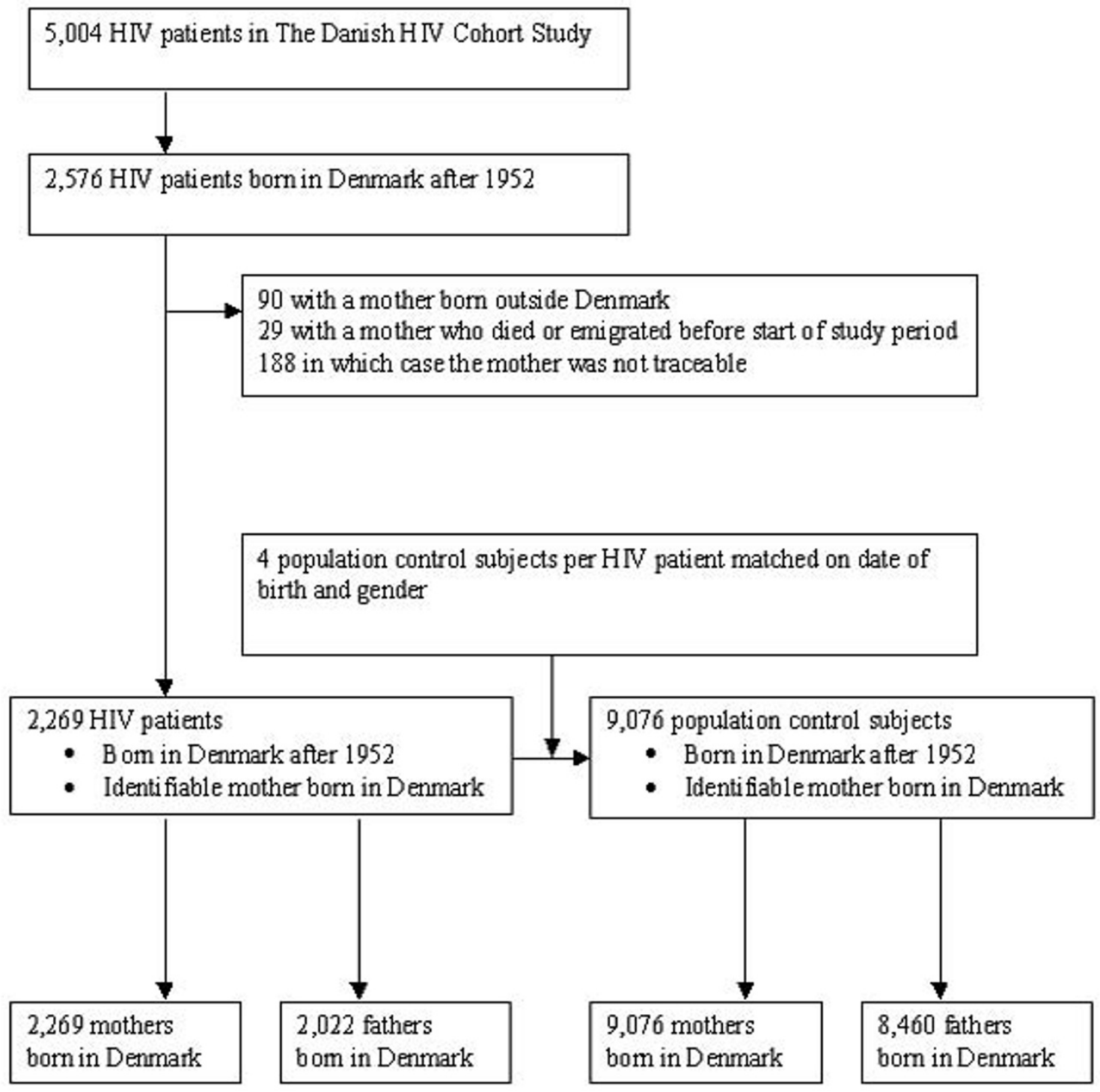

Figure 1 Summary of the study design.

the IRR was adjusted for: age at start of observation (continuous variable) as well as year of birth of the parent divided into the following decades: - before1920, 19201930, 1930-1940, 1940-1950, after 1950.

Cox regression analyses were stratified on route of $\mathrm{HIV}$ transmission in the HIV patient (homosexual, heterosexual or intravenous drug abuse (IVD)).

Statistical analyses were performed using SPSS version 17.0 and $R$ version 2.8.1. The study was approved by the Danish Data Protection Agency (Denmark has no Institutional review boards).

\section{Results}

Of the 5,004 HIV patients in the Danish HIV Cohort Study 2,576 were born in Denmark after 1952. Of these
2,576 patients, 90 had a mother born outside Denmark, 29 mothers had died or emigrated from Denmark before the start of the study period (1 January 1977) and 188 had mothers, who were untraceable in The Danish Civil Registration System leaving 2,269 individuals in the study population (figure 1). For these individuals we identified 9,076 population controls. The demographics of the two populations are shown in table 1 .

We identified 2,269 mothers and 2,022 fathers of HIVinfected patients as well as 9,076 mothers and 8,460 fathers of control subjects (figure 1 and table 2). The parents of the HIV-infected patients were almost the same age as that of the population controls (Table 2). Due to the study design Denmark was registered as country of birth in all parents. The median time of follow up was 
Table 1: Characteristics of HIV-infected patients and population controls.

\begin{tabular}{lcc}
\hline & HIV-infected patients & Control subjects \\
\hline Number of study subjects & 2,269 & 9,076 \\
Males (number (\%)) & $1,895(83.5)$ & $33.580(83.5)$ \\
Median age at index date (years (IQR)) & $33.8(29.2-38.7)$ & \\
Route of infection: & $1,205(53.1)$ & $555(24.5)$ \\
$\quad$ Homosexual (number (\%)) & $336(14.8)$ \\
Heterosexual (number (\%)) & $173(7.6)$ \\
Injection drug abuse (number (\%)) & \\
Other/unknown (number (\%)) & \\
\hline
\end{tabular}

almost 30 years in all groups and very few subjects were lost to follow up.

During the study period the overall risk of MI was 2.08/ 1,000 PYR (95\% CI: 1.75-2.48) versus 1.70/1,000 PYR (95\% CI: 1.54-1.86) for mothers of HIV patients and control subjects and 5.20/1,000 PYR (95\% CI: 4.60-5.87) versus 5.07/1,000 PYR (95\% CI: 4.78-5.38) for fathers of HIV patients and control subjects (Table 2).

Risk of MI was significantly higher in mothers of HIVinfected patients compared to the control subjects (adjusted relative risk, 1.31; 95\% CI: 1.08-1.60) (Table 3 and Figure 2). The risk of MI was highest in mothers of HIV patients who reported heterosexual contact (adjusted relative risk, 1.59; 95\% CI: 1.07-2.35) and IVD (adjusted relative risk, 1.63; 95\% CI: 1.02-2.60) as route of HIV infection (Table 3).

Risk of MI in fathers of HIV-infected patients was almost similar to that of control subjects (adjusted relative risk, 1.04, 95\% CI: 0.90-1.19) (Table 3 and Figure 2). However having an offspring reporting IVD as route of infection, seemed to substantially increase the risk of MI in the fathers (adjusted relative risk, 1.42; 95\% CI: 1.012.00).

\section{Discussion and Conclusion}

In this population based nation wide cohort study we found an increased risk of MI in mothers of HIV-infected patients compared with mothers of the general population. The increased risk of MI was mainly seen in mothers of HIV patients reporting to be infected heterosexually or by IVD. In the fathers the increased risk of MI was only seen in case the offspring reported IVD as route of HIV infection.

The strength of our study is the nationwide population based design as well as a long and complete follow-up and the access to valid data on family members. We included parents of HIV patients and parents of a well-matched population control cohort. Further we were able to stratify our results on several important factors as parental gender, route of HIV transmission as well as calendar periods. As immigrants may retain higher risk of a disease due to susceptibility periods during childhood for

Table 2: Characteristics of parents of HIV-infected patients and population controls.

\begin{tabular}{|c|c|c|c|c|}
\hline & \multicolumn{2}{|c|}{ Mothers of } & \multicolumn{2}{|c|}{ Fathers of } \\
\hline & HIV-infected patients & Control subjects & HIV-infected patients & Control subjects \\
\hline No of parents & 2,269 & 9,076 & 2,022 & 8,460 \\
\hline Median age at index date (years (IQR)) & $38.3(32.3-44.9)$ & $38.7(32.4-45.3)$ & $41.5(34.6-49.1)$ & $41.9(34.6-49.2)$ \\
\hline $\begin{array}{l}\text { Number in whom observation time started after } \\
\text { 1. January } 1977(\%)\end{array}$ & $197(7.9)$ & $699(7.7)$ & $200(8.8)$ & $773(8.1)$ \\
\hline First admission with Ml after index date: & $129(5.7)$ & $434(4.8)$ & $257(12.7)$ & $1,085(12.8)$ \\
\hline Emigration during follow-up, $\mathrm{N}(\%)$ & $19(0.8)$ & $35(0.4)$ & $18(0.9)$ & $44(0.5)$ \\
\hline Lost to follow-up, N (\%) & $0(0.0)$ & $1(0.0)$ & $1(0.0)$ & $3(0.0)$ \\
\hline \multicolumn{5}{|l|}{ Duration of follow up } \\
\hline Duration of follow-up, person years & 61,900 & 256,033 & 49,443 & 213,883 \\
\hline Duration of follow-up, median years (IQR) & $31.4(25.9-31.4)$ & $31.4(28.3-31.4)$ & $29.9(18.7-31.4)$ & $31.0(20.6-31.4)$ \\
\hline Overall risk of $\mathrm{Ml}$, per 1,000 PYR $(95 \% \mathrm{Cl})$ & $2.08(1.75-2.48)$ & $1.70(1.54-1.86)$ & $5.20(4.60-5.87)$ & $5.07(4.78-5.38)$ \\
\hline
\end{tabular}


Table 3: Risk of MI in parents of HIV- infected patients and population controls.

\begin{tabular}{|c|c|c|c|c|}
\hline & \multicolumn{2}{|c|}{ Mothers: } & \multicolumn{2}{|c|}{ Fathers: } \\
\hline & Unadjusted IRR (95\% Cl) & Adjusted IRR $(95 \% \mathrm{CI})$ & Unadjusted IRR (95\% Cl) & Adjusted IRR $(95 \% \mathrm{Cl})$ \\
\hline All parents & $1.25(1.03-1.52)$ & $1.31(1.08-1.60)$ & $1.03(0.90-1.18)$ & $1.04(0.901 .19)$ \\
\hline $\begin{array}{l}\text { Parents of homosexual } \\
\text { patients }\end{array}$ & $1.11(0.84-1.48)$ & $1.10(0.82-1.47)$ & $0.98(0.81-1.18)$ & $0.94(0.78-1.13)$ \\
\hline $\begin{array}{l}\text { Parents of heterosexual } \\
\text { patients }\end{array}$ & $1.46(0.99-2.15)$ & $1.59(1.07-2.35)$ & $1.02(0.77-1.35)$ & $1.07(0.81-1.41)$ \\
\hline Parents of IV-drug addicts & $1.31(0.82-2.08)$ & $1.63(1.02-2.60)$ & $1.31(0.94-1.83)$ & $1.42(1.01-2.00)$ \\
\hline
\end{tabular}

some diseases as well as the potential effect of acculturation, immigrants were excluded from our study [22,23]. In the start of the epidemic in the 1950s coronary heart disease was associated with high socio-economic status, but over time became a disease of the lower social classes. This, as well as the fact that treatment and prevention of ischaemic heart disease has changed considerably over time, makes control of calendar periods essential $[8,24]$. We are not aware of other studies with a similar design.

Our study has some limitations. To identify patients with the MI diagnosis we relied on hospital registry based discharge diagnoses, which may not be entirely accurate and includes a risk of incorrectly registered diagnoses due to pre-hospital death. Importantly though we used the same source of data to ascertain MI for all study objects. Furthermore identification of MI on behalf of discharge diagnoses has previously been shown to be valid [25]. We could not adjust for specific indicators of social class and socio-economic status such as parental education, occupation, family income, housing conditions, maternal marital status or illegitimacy. However, reported route of HIV infection in the offspring may act as a surrogate marker for socio-economic status.

Denmark harbours well-designed registries, which provide full access to data on all inhabitants concerning vital status and hospital contacts. As the Danish National Hospital Registry was not initiated until January 1977, some of the study subjects (i.e. the parents) might have had MI prior to study inclusion. These subjects are at increased risk of MI and ideally should have been excluded. However, as the Danish National Hospital Registry does not allow us to distinguish between first and subsequent epi-
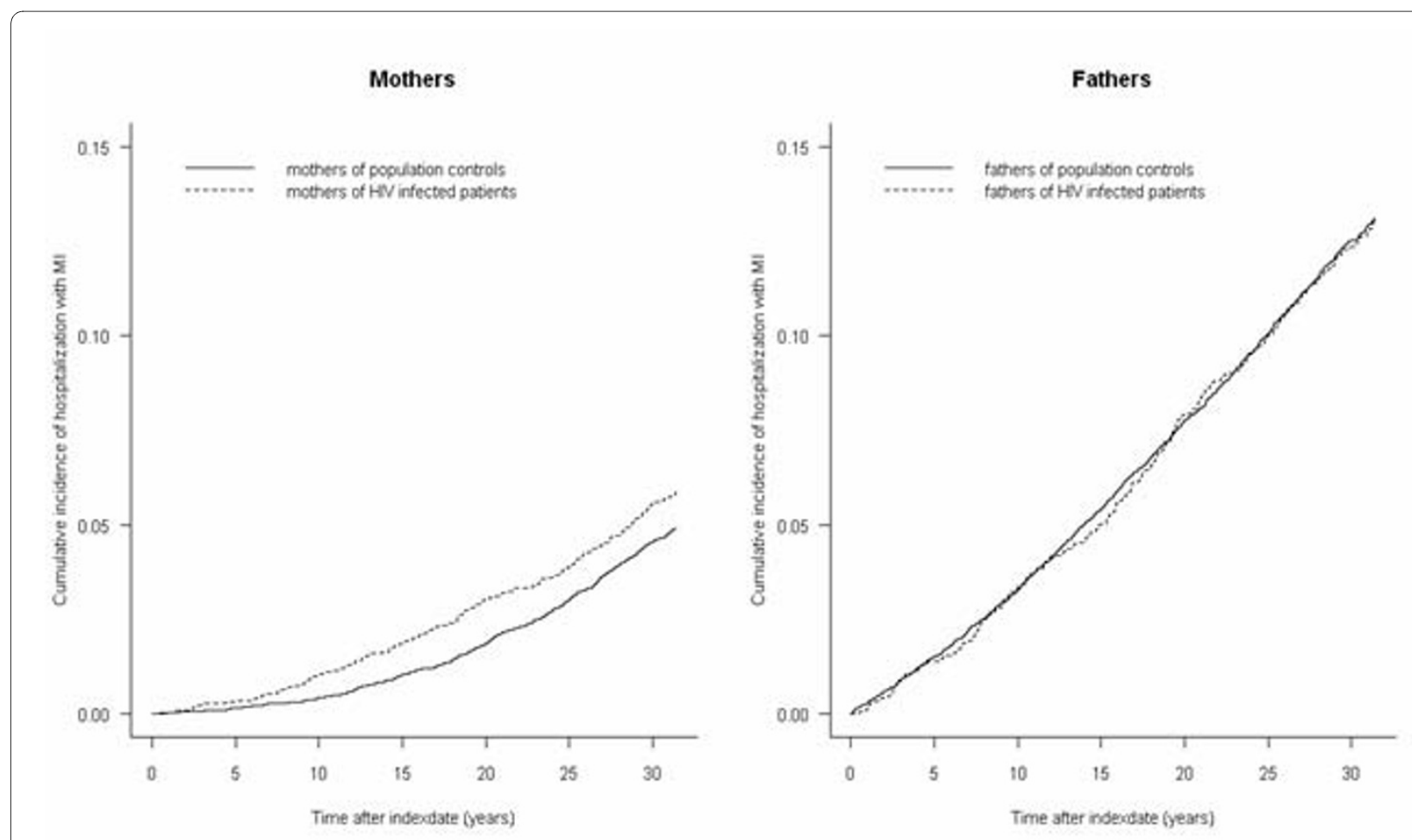

Figure 2 Cumulative incidence of hospitalization with $\mathrm{MI}$ in mothers and fathers. 
sodes of MI in case the first MI occurred before 1977, we have no means of excluding these patients. Nevertheless, this phenomenon could hardly have biased our results substantially as the study subjects were young at inclusion, which makes previous episodes of MI unlikely. Further, age at study inclusion did not differ markedly between the compared groups (mothers versus mothers, fathers versus fathers) and therefore the proportion of post MIs misclassified as primary MI probably did not differ between groups. The relative risk measures therefore would remain rather unchanged even in case of inclusion of some post MI subjects. Parents were not included in the study if they had never been registered as parents in the Danish Civil Registration System, or had died prior to year 1977 as diagnoses of MI in the Danish National Hospital Registry were first available from that year. In 188 cases $(7.6 \%)$ we were not able to trace the mothers in The Danish Civil registration System. We presume that the bias this may introduce is equivalent in the patient/control populations and does not influence our estimates.

In general the absolute risk of MI is higher in males than in females. However, in our study the increase in relative risk of MI was substantially higher in the mothers compared to the fathers. Several factors may explain this observation. First low socio-economic class, associated with particular lifestyle patterns, has been described as a stronger risk factor of MI for women than for men [26]. Second the offspring may be more prone to share life style characteristics with their mothers than their fathers possible due to a preponderance of single family homes with mothers raising the children. And third the absolute risk of MI was almost three times higher in the fathers compared to the mothers. Therefore a minor increase in absolute risk of $\mathrm{MI}$ in the mothers will result in a greater increase in relative risk in this population compared to the fathers.

Although ischaemic heart disease manifests itself in adulthood, the disease and underlying atherosclerosis, develops throughout life [23]. An increased risk of MI has previously been shown to be associated with lower social class in adulthood $[22,23,27]$. However, adverse circumstances during pregnancy and childhood, including poor socio-economic conditions, seem to be important determinants of risk of adult cardiovascular disease. These risk factors are not merely due to the continuity of disadvantage throughout life $[8,23,24,28]$. In a study by Kaplan et al it was suggested that HIV-infected individuals from economically disadvantaged populations bear a disproportionate burden of risk factors that might explain the association of MI and HIV [27]. In addition to this it has previously been established that the prevalence of smokers are consistently higher in HIV patients than in agematched controls $[14,27,29-31]$. We cannot exclude that smoking may be a major contribution to the increased risk of MI in parents of HIV patients acting independently of other risk factors.

Our results showed a strong association between IVD as route of HIV infection in the offspring and risk of MI in both mothers and fathers of HIV patients. A strong association between initiation of IVD in the offspring and adverse socio-environmental factors in childhood has been described and this association probably explains the association observed in our study $[32,33]$.

Our study cannot unambiguously discriminate to what extend genetic and environmental factors exert their impact on risk of MI in the parents of HIV patients. But the findings imply that shared socio-economic disadvantages to some extent explain the excess risk of MI observed in the mothers. The genetic element in MI is not to be questioned but to our knowledge no genetic factors have been described, which is associated with increased risk of both HIV acquisition and MI. However, health-risk behaviours are frequently interrelated [34] and tendency to "risk taking behaviour" has been explained as a result of a complex combination of social (e.g. socio-economic and environmental factors), genetic and developmental factors [35-39]. In that case initiating IVD, sharing needles and having sex without barrier protection as well as heavy smoking, alcohol consumption, inappropriate diet and physical inactivity, could all be a result of the same genetic predisposition.

The increased risk of MI in HIV infected individuals has mainly been ascribed to the HIV infection per se and exposure to HAART $[4-7,11,12,15-17,40]$. Additionally it has been questioned whether a HIV-positive status simply serves as a marker for differences in the prevalence of conventional risk factors such as smoking [29]. We found an increased risk of MI in mothers of HIV patients of almost the same order (IRR: 1.31) as that seen in their HIV infected offspring when not on HAART (IRR: 1.39) [4]. Our data therefore indicate that a main proportion of the increased risk of MI in these mothers and their HIVinfected offspring may stem from the same family related life style factors.

The implications of our findings extend beyond establishing the risk of MI in the parents of the HIV infected patients. Recent studies suggest premature aging, accelerated cognitive decline, increased risk of non-AIDS associated cancers and osteoporosis in HIV infected patients despite successful HAART [41]. These studies may potentially be hampered by substantial influence from family related risk factors as well. Thus our data indicate that the association between risk for common diseases and HIV exposure may make it difficult to definitively establish HIV or antiretroviral drugs as causal risk factors for comorbidity in HIV infected patients. 
In conclusion, mothers of HIV-infected patients have increased risk of MI. We presume, that the increased risk is related to family related life style risk factors, some of which may also influence the risk of MI in the HIVinfected patients. Thus, a major fraction of the increased risk of MI observed in $\mathrm{HIV}$-infected patients may stem from non-HIV-related factors.

\section{Competing interests}

NO has received research funding from Roche, Bristol-Myers Squibb, Merck Sharp \& Dohme, GlaxoSmithKline, Abbott, Boehringer Ingelheim, Janssen-Cilag and Swedish Orphan. CP has received research funding from Abbott, Roche, Bristol-Myers Squibb, Merck Sharp \& Dohme, GlaxoSmithKline, Swedish Orphan and Boehringer Ingelheim. JG has received research funding from Abbott, Roche, Bristol-Myers Squibb, Mecrk Sharp \& Dohme, Pharmasia, GlaxoSmithKline, Swedish Orphan and Boehringer Ingelheim. LDR, LHO, CP, GK and JJ report no conflicts of interest.

\section{Authors' contributions}

Conception and design: LDR, LHO, NO. Analysis and interpretation of the data: $L D R, L H O, N O$. Drafting of the article: LDR Critical revision of the article for important intellectual content: LDR, LHO, CP, JG, GK, JJ, NO. Provision of study materials or patients: CP, GK, JG, JJ, NO. Statistical expertise: LDR, LHO, NO. Obtaining of funding: NO. Administrative, technical, or logistic support: LDR, NO. Collection and assembly of data: CP, GK, JG, JJ, NO. All authors read and approved the final manuscript.

\section{Acknowledgements}

We thank the staff of our clinical departments for their continuous support and enthusiasm, Preben and Anna Simonsen's Foundation, The Novo Nordisk Foundation as well as University of Southern Denmark and the Clinical Institute of Copenhagen University for financial support.

\section{Centres in the Danish HIV Cohort Study:}

Departments of Infectious Diseases at Copenhagen University Hospitals, Rigshospitalet (J Gerstoft, N Obel) and Hvidovre (G Kronborg), Odense University Hospital (C Pedersen), Aarhus University Hospitals, Skejby (CS Larsen) and Aalborg (G Pedersen), Herning Hospital (AL Laursen), Helsingør Hospital (L Nielsen) and Kolding Hospital (J Jensen).

\section{Author Details}

1Department of Infectious Diseases, Odense University Hospital, Odense, Denmark, 2Department of Infectious Diseases, Copenhagen University Hospital, Rigshospitalet, Denmark, '3Department of Infectious Diseases, Copenhagen University Hospital, Hvidovre, Denmark and ${ }^{4}$ Department of Infectious Diseases, Kolding Sygehus, Kolding, Denmark

Received: 4 March 2010 Accepted: 14 June 2010

Published: 14 June 2010

\section{References}

1. Lohse N, Hansen AB, Pedersen G, Kronborg G, Gerstoft J, Soerensen HT, Vaeth $M$, Obel N: Survival of persons with and without HIV infection in Denmark, 1995-2005. Ann Intern Med 2007, 146:87-95.

2. Grinspoon SK: Metabolic syndrome and cardiovascular disease in patients with human immunodeficiency virus. Am J Med 2005, 118(Suppl 2):23S-8S.

3. Deeks SG: Antiretroviral treatment of HIV infected adults. BMJ 2006, 332:1489.

4. Obel N, Thomsen HF, Kronborg G, Larsen CS, Hildebrandt PR, Soerensen HT, Gerstoft J: Ischemic heart disease in HIV-infected and HIVuninfected individuals: a population-based cohort study. Clin Infect Dis 2007, 44:1625-31.

5. Triant VA, Lee H, Hadigan C, Grinspoon SK: Increased acute myocardial infarction rates and cardiovascular risk factors among patients with human immunodeficiency virus disease. J Clin Endocrinol Metab 2007, 92:2506-12.

6. Friis-Moller N, Sabin CA, Weber R, d'Arminio-Monforte A, El-Sadr WM, Resiss P, Thiebaut R, Morfeldt NL, De-Wit S, Pradier C, Calvo G, Law MG,
Kirk O Phillips AN, Lundgren JD: Combination antiretroviral therapy and the risk of myocardial infarction. N Eng/ J Med 2003, 349:1993-2003.

7. D:A:D Study Group, Sabin CA, Worm SW, Weber R, Reiss P, El-Sadr W, Dabis F, De Wit S, Law M, D'Arminio Monforte A, Friis-Møller N, Kirk O, Pradier C, Weller I, Phillips AN, Lundgren JD: Use of nucleoside reverse transcriptase inhibitors and risk of myocardial infarction in HIVinfected patients enrolled in the D:A:D study: a multi-cohort collaboration. Lancet 2008, 371(9622):1417-26.

8. Jousilahti P, Puska P, Vartiainen E, Pekkanen J, Tuomilehto J: Parental history of premature coronary heart disease: an independent risk factor of myocardial infarction. J Clin Epidemiol 1996, 49:497-503.

9. Bozzette SA, Ake CF, Tam HK, Chang SW, Louis TA: Cardiovascular and cerebrovascular events in patients treated for human immunodeficiency virus infection. N Engl J Med 2003, 348:702-10.

10. Kwong GP, Ghani AC, Rode RA, Bartley LM, Cowling BJ, da Silvia B, Donelly CA, van Sighem Al, Cameron DW, Danner SA, de Wolf F, Anderson RM: Comparison of the risks of atherosclerotic events versus death from other causes associated with antiretroviral use. AIDS 2006, 20:1941-50,

11. Holmberg SD, Moorman AC, Williamson JM, Tong TC, Ward DJ, Wood KC, Greenberg AE, Jansen RS, HIV Outpatient Study (HOPS): Protease inhibitors and cardiovascular outcomes in patients with HIV-1. Lancet 2002, 360:1747-8.

12. Iloeje UH, Yuan Y, L'italien G, Mauskopf J, Holmberg SD, Moorman AC, Wood KC, Moore RD: Protease inhibitor exposure and increased risk of cardiovascular disease in HIV-infected patients. HIV Med 2005, 6:37-44

13. Data Collection on Adverse Events of Anti-HIV Drugs Study Group, Sabin CA, d'Arminio-Monforte A, Friis-Moller N, Weber R, El-Sadr WM, Reiss P, Kirk O, Mercie P, Law MG, De Wit S, Pradier C, Phillips AN, Lundgren JD: Changes over time in risk factors for cardiovascular disease and use of lipid-lowering drugs in HIV-infected individuals and impact on myocardial infarction. Clin Infect Dis 2008, 46:1101-10.

14. Saves M, Chene G, Ducimetiere P, Leport C, Le Moal G, Amouyel P, Arveiler D, Ruidavets JB, Reynes J, Bingham A, Raffi F, French WHO MONICA Project and the APROCO (ANRS EP11) Study Group: Risk factors for coronary heart disease in patients treated for human immunodeficiency virus infection compared with the general population. Clin Infect Dis 2003, 37:292-8.

15. Escaut L, Monsuez JJ, Chironi G, Merad M, Teicher E, Smadja D, Simon A, Vittecoq D: Coronary artery disease in HIV infected patients. Intensive Care Med 2003, 29:969-73.

16. Varriale P, Saravi G, Hernandez E, Carbon F: Acute myocardial infarction in patients infected with human immunodeficiency virus. Am Heart $J$ 2004, 147:55-9.

17. Barbaro G, Di Lorenzo G, Cirelli A, Grisorio B, Lucchini A, Hazra C, Barbarini G: An open-label, prospective, observational study of the incidence of coronary artery disease in patients with HIV infection receiving highly active antiretroviral therapy. Clin Ther 2003, 25:2405-18.

18. Obel N, Engsig FN, Rasmussen LD, Larsen MV, Omland LH, Sorensen HT: Cohort Profile: The Danish HIV Cohort Study. Int J Epidemiol in press. PMID: 18799495

19. Frank L: Epidemiology. When an entire country is a cohort. Science 2000, 287:2398-9.

20. Andersen TF, Madsen $M$, Jorgensen J, Mellemkjaer L, Olsen JH: The Danish National Hospital Register. A valuable source of data for modern health sciences. Dan Med Bull 1999, 46:263-8.

21. Kleinbaum DG, Klein M: Competing Risk Survival Analysis. Survival Analysis: A Self-Learning Text. 2nd edition. New York: Springer Science+Business Media, LLC; 2005:391-461.

22. Diez Roux AV, Detrano R, Jackson S, Jacobs DR Jr, Shea S, Szklo M: Acculturation and socioeconomic position as predictors of coronary calcification in a multiethnic sample. Circulation 2005, 112:1557-65.

23. Galobardes B, Lynch JW, Smith GD: Childhood socioeconomic circumstances and cause-specific mortality in adulthood: systematic review and interpretation. Epidemiol Rev 2004, 26:7-21.

24. Burr ML, Sweetnam PM: Family size and paternal unemployment in relation to myocardial infarction. J Epidemiol Community Health 1980, 34:93-5.

25. Madsen M, Davidsen M, Rasmussen S, Abildstrom SZ, Osler M: The validity of the diagnosis of acute myocardial infarction in routine statistics: a comparison of mortality and hospital discharge data with the Danish MONICA registry. J Clin Epidemiol 2003, 56:124-30. 
26. Brezinka V, Padmos I: Coronary heart disease risk factors in women. Eur Heart J 1994, 15:1571-84.

27. Kaplan RC, Kingsley LA, Sharrett AR, Li X, Lazar J, Tien PC, Mack WJ, Cohen $\mathrm{MH}$, Jacobsen L, Gange SJ: Ten-year predicted coronary heart disease risk in HIV-infected men and women. Clin Infect Dis 2007, 45:1074-81.

28. Smith GD, Hart C, Blane D, Hole D: Adverse socioeconomic conditions in childhood and cause specific adult mortality: prospective observational study. BMJ 1998, 316:1631-5.

29. Currier JS, Lundgren JD, Carr A, Klein D, Sabin CA, Sax PE, Schouten JT, Smieja M, Working Group 2: Epidemiological evidence for cardiovascular disease in HIV-infected patients and relationship to highly active antiretroviral therapy. Circulation 2008, 118:e29-e35.

30. Friis-Moller $\mathrm{N}$, Weber R, Reiss $\mathrm{P}$, Thiebaut R, Kirk O, d'Arminio-Monforte $A$ Pradier C, Morfeldt L, Mateu S, Law M, El-Sadr W, De Wit S, Sabin CA, Phillips AN, Lundgren JD, DAD study group: Cardiovascular disease risk factors in HIV patients-association with antiretroviral therapy. Results from the DAD study. AIDS 2003, 17:1179-93.

31. Webb MS, Vanable PA, Carey MP, Blair DC: Cigarette smoking among HIV+ men and women: examining health, substance use, and psychosocial correlates across the smoking spectrum. J Behav Med 2007, 30:371-83.

32. Cadoret RJ, Troughton E, O'Gorman TW, Heywood E: An adoption study of genetic and environmental factors in drug abuse. Arch Gen Psychiatry 1986, 43:1131-6.

33. Wood E: Gender and risk factors for initiation into injection drug use. Drug Alcohol Rev 2007, 26:333-4.

34. Eaton DK, Kann L, Kinchen S, Ross J, Hawkins J, Harris WA, Lowry R McManus T, Chyen D, Shanklin S, Lim C, Grumbaum JA, Wechsler H: Youth risk behavior surveillance - United States, 2005. J Sch Health 2006 , 76:353-72.

35. Cadoret RJ, Yates WR, Troughton E, Woodworth G, Stewart MA: Adoption study demonstrating two genetic pathways to drug abuse. Arch Gen Psychiatry 1995, 52:42-52.

36. Donovan JE, Jessor R: Structure of problem behaviour in adolescence and young adulthood. J Consult Clin Psychol 1985, 53:890-904.

37. Farrell $A D$, Danish $S J$, Howard CW: Relationship between drug use and other problem behaviours in urban adolescents. $J$ Consult Clin Psychol 1992, 60:705-12.

38. Jessor R: Risk behavior in adolescence: a psychosocial framework for understanding and action. J Adolesc Health 1991, 12:597-605.

39. Santelli J, Carter M, Orr M, Dittus P: Trends in sexual risk behaviours, by nonsexual risk behaviour involvement, U.S. high school students, 1991-2007. J Adolesc Health 2009, 44:372-9.

40. Mary-Krause M, Cotte L, Simon A, Partisani M, Costagliola D: Increased risk of myocardial infarction with duration of protease inhibitor therapy in HIV-infected men. AIDS 2003, 17:2479-86.

41. Deeks SG, Philips AN: HIV infection, antiretroviral treatment, aging and non-AIDS related morbidity. BMJ 2009, 338:a3172.

\section{Pre-publication history}

The pre-publication history for this paper can be accessed here: http://www.biomedcentral.com/1471-2334/10/169/prepub

\section{doi: $10.1186 / 1471-2334-10-169$}

Cite this article as: Rasmussen et al., Risk of Myocardial Infarction in Parents of HIV-infected Individuals: a population-based Cohort Study BMC Infectious Diseases 2010, 10:169

\section{Submit your next manuscript to BioMed Central} and take full advantage of:

- Convenient online submission

- Thorough peer review

- No space constraints or color figure charges

- Immediate publication on acceptance

- Inclusion in PubMed, CAS, Scopus and Google Scholar

- Research which is freely available for redistribution

Submit your manuscript at www.biomedcentral.com/submit
C) Biomed Central 